\title{
Maria M. Mota: Bringing Plasmodium Liver Infection to the Centre Stage of Malaria Research
}

\author{
Silvia Portugal ${ }^{1}$, Ana Rodriguez ${ }^{2}$ and Miguel Prudêncio ${ }^{3 *}$ \\ ${ }^{1}$ Max Planck Institute for Infection Biology, Berlin, Germany, ${ }^{2}$ Department of Microbiology, New York University School of \\ Medicine, New York City, NY, United States, ${ }^{3}$ Instituto de Medicina Molecular, Faculdade de Medicina, Universidade de \\ Lisboa, Lisboa, Portugal
}

Keywords: malaria, liver stage, sporozoites, Plasmodium, hepatocyte

\section{INTRODUCTION}

Mammalian infection by malaria parasites is initiated by the injection of Plasmodium sporozoites into the host's skin in preparation for a blood meal by an infected female Anopheles mosquito. Sporozoites then travel to the liver, where they invade hepatocytes and initiate an asymptomatic

Edited by:

Tania F. De Koning-Ward, Deakin University, Australia

Reviewed by:

Volker Theo Heussler, University of Bern, Switzerland Purnima Bhanot, Rutgers Biomedical and Health Sciences, United States

${ }^{*}$ Correspondence: Miguel Prudêncio mprudencio@medicina.ulisboa.pt

Specialty section: This article was submitted to Parasite and Host, a section of the journal

Frontiers in Cellular and Infection Microbiology

Received: 09 January 2022 Accepted: 24 January 2022 Published: 08 February 2022

Citation:

Portugal S, Rodriguez A and Prudêncio M (2022) Maria M. Mota: Bringing Plasmodium Liver Infection to the Centre Stage of Malaria Research. Front. Cell. Infect. Microbiol. 12:851484. doi: 10.3389/fcimb.2022.851484 phase of asexual replication, known as the liver stage of infection. This process culminates in the release of thousands of newly-formed red blood cell-infective merozoites, which are responsible for malaria-associated pathology (Prudencio et al., 2006). Although the liver stage of the Plasmodium life cycle constitutes the initial and obligatory step of mammalian infection by malaria parasites, it remained as a biological black box for decades since its discovery by Shortt, Garnham and their team in 1948 (Shortt et al., 1948). Its clinically silent nature, coupled with the inherent limitations of its experimental address, meant that liver infection by Plasmodium remained largely unknown by researchers for decades. However, it is now known that this pivotal phase of the malaria parasite's life cycle plays critical roles in the establishment of mammalian infection by Plasmodium, in the host's response to the parasite, and in the outcome of disease. The Plasmodium-host hepatic interface is now commonly regarded not only as an ideal target for malaria prophylaxis and vaccination, but also as the site where a unique and extremely rich array of molecular interactions take place. And few people have contributed as much as Maria M. Mota to unveiling key features of the liver stage of the malaria parasite's life cycle. By engaging the most advanced in vitro and rodent models of Plasmodium infection (Langhorne et al., 2011; Prudencio et al., 2011; Zuzarte-Luis et al., 2014), Maria decisively helped to bring this once-relatively obscure phase of the parasite's life cycle to the limelight of malaria research.

Maria Manuel Mota obtained her BSc in Biology and her MSc in Immunology in 1992 and 1994, respectively, at the University of Porto, Portugal, followed by a $\mathrm{PhD}$ in Molecular Parasitology by the University College London in 1998. She then carried out her post-doctoral studies on hostparasite interactions in Victor Nussenzweig's lab at the New York University Medical School from 1999 to 2002. On this year, she returned to her home country of Portugal to become a group leader, initially at Instituto Gulbenkian de Ciência (IGC), and subsequently at Instituto de Medicina Molecular (iMM), where she became the Executive Director in 2014.

The authors of this article have been fortunate enough to interact closely with Maria M. Mota at different stages of her career. Maria spent part of her time at the laboratory of AR during her postdoctoral studies at the New York University; MP joined Maria's group as a postdoctoral researcher 
soon after she became an independent scientist, and was a staff scientist in her laboratory before becoming an independent group leader at Lisbon's iMM; and SP was Maria's PhD student at a time when her position as a key player in malaria research was well solidified and internationally recognized. Each one of us has had the unique opportunity to perceive Maria's unique scientific drive, her contagious enthusiasm, and her unabashed commitment to research. We are all indebted to Maria for her continued support of our own scientific careers but, above all, we feel very fortunate to have witnessed some of the most remarkable discoveries made in the field of liver stage Plasmodium infection. As Maria's career as an independent scientist reaches its $20^{\text {th }}$ anniversary, this is our account of some of her most relevant scientific achievements of the last two decades.

\section{RE-DESIGNING THE LIFE CYCLE OF MALARIA PARASITES}

In 2001, Maria M. Mota, working in the laboratory of AR, demonstrated for the first time that Plasmodium sporozoites traverse several hepatocytes before productively invading a final cell (Mota et al., 2001), and suggested that this migration might activate sporozoites for productive invasion of hepatocytes (Mota et al., 2002). Maria's work subsequently showed that hepatocyte growth factor (HGF), a molecule released by host cells upon wounding by traversing sporozoites, interacts with its receptor MET to promote the parasites' intrahepatic development (Carrolo et al., 2003) and to protect Plasmodium-infected cells from apoptosis (Leiriao et al., 2005). While the exact reasons for, and the implications of the parasite's migratory behavior remain incompletely elucidated, in the words of Victor Nussenzweig, Maria M. Mota's supervisor and mentor at the New York University, "Maria's finding literally changed the textbook representation of the life cycle of Plasmodium parasites".

\section{HOST GENES AND DRUG TARGETS}

As Maria initiated her independent research career in Portugal, her focus on the study of the liver stage of Plasmodium infection intensified and expanded, and she soon reported the first transcriptome profile of the hepatic host cell throughout infection by malaria parasites (Albuquerque et al., 2009). Soon thereafter, Maria's lab pioneered the use of RNA interference (RNAi) to identify host factors at play during hepatic Plasmodium infection. An RNAi screen of the entire human kinome implicated five host kinases in this process, further establishing a role for PKCs on hepatocyte invasion by sporozoites (Prudencio et al., 2008). A parallel RNAi screen additionally unveiled the hepatic host's scavenger receptor SR-BI as playing a critical role in both the sporozoite's ability to invade liver cells and to develop intracellularly (Rodrigues et al., 2008). During this period, the work of Maria's team also led to the identification of genistein as a potential drug for malaria prophylaxis (Cunha-Rodrigues et al., 2008), to the demonstration that Plasmodium liver infection can be inhibited by a small molecule inhibitor of signal peptide peptidase, with an impact on malaria severity (Parvanova et al., 2009), and that CpG phosphothioate oligodeoxynucleotides can act directly on Plasmodium sporozoites to inhibit their gliding motility, cell traversal ability and capacity to invade hepatic cells (Liehl et al., 2010). In 2012, she was deeply involved in pioneering drug screens targeting the liver stage of the parasite's life cycle, which identified decoquinate as a potent multi-stage antiplasmodial drug (da Cruz et al., 2012), and revealed that hepatic malaria parasites are vulnerable to diverse chemical scaffolds (Derbyshire et al., 2012). One year later, her lab identified torins as fast-acting anti-plasmodial compounds that efficiently target the parasite's liver and blood stages in a manner that is independent of those drug's canonical target, the mammalian target of rapamycin (mTOR) kinase (Hanson et al., 2013). Collectively, these and other achievements helped to define Maria's position at the forefront of liver stage Plasmodium infection research, a status that never ceased to solidify.

\section{THE PATHOGENESIS OF SEVERE MALARIA}

Always acutely aware of the pathology that ensues during the erythrocytic phase of the malaria parasite's life cycle, Maria's lab helped unveil heme oxygenase-1 (HO-1) as a host factor that not only promotes liver infection by Plasmodium parasites (Epiphanio et al., 2008), but that also plays a crucial role in the development of experimental cerebral malaria (Pamplona et al., 2007). A few years later, the team established a DBA/2 mouse model for the study of Plasmodium-induced experimental acute lung injury, showing that this life-threatening condition is promoted by the host's vascular endothelial growth factor (VEGF), and can be inhibited by carbon monoxide's anti-inflammatory action (Epiphanio et al., 2010). These achievements furthered our knowledge of malaria pathogenesis, and remain as a testimony of Maria's ability to think beyond the liver stage of infection and seeking solutions to combat the most grievous forms of malaria disease.

\section{HEPATOCYTE INVASION BY PLASMODIUM SPOROZOITES}

One of the questions that had puzzled the community for decades was how Plasmodium sporozoites could engage into a phase of intra-hepatic differentiation and multiplication so promptly after transitioning from the mosquito salivary glands to hepatocytes. Maria's lab contributed pivotally to our current knowledge of the molecular determinants of this process, by unveiling a Pumilio-2 (Puf2)-dependent post-translational repression mechanism that controls that transition (GomesSantos et al., 2011). Very recently, her team challenged the dogma that hepatocytes are passive players during the process of their invasion by sporozoites. This work showed that the poreforming activity of the parasite's exported protein 2 (EXP2) triggers a response from the hepatic host cell, which leads to the production of acid sphingomyelinase. This enzyme then plays a 
critical role in the repair of the host cell membrane, which is key for sporozoite invasion and establishment in hepatocytes (MelloVieira et al., 2020). This finding is a perfect illustration of Maria's ability to push the boundaries of knowledge beyond the status $q u o$, by unveiling an active role for the hepatic host cell in a process long thought to depend solely on the parasite.

\section{NEW TOOLS TO STUDY LIVER INFECTION BY PLASMODIUM}

Throughout her career, Maria contributed several new instruments to the fight against malaria, thorough the establishment of new tools and platforms for the investigation of Plasmodium liver infection. Among other achievements, she and her team demonstrated the usefulness of transgenic malaria parasites expressing fluorescent or luminescent reporter genes as invaluable tools to identify and quantify Plasmodium infection, not only in the liver (Prudencio et al., 2008; Ploemen et al., 2009), but also in the blood (Zuzarte-Luis et al., 2014). During a sabbatical in Sangeeta Bhatia's laboratory at the Massachusetts Institute of Technology (MIT), Maria contributed to the generation of a human liver in vitro platform that is able to sustain the development of human malaria parasites (March et al., 2013), and showed that human induced pluripotent stem cell-derived hepatocyte-like cells support infection by multiple Plasmodium sporozoite species (Ng et al., 2015). These achievements, alongside the more recent establishment of a humanized mouse model bearing an ectopic artificial liver that can be infected by human malaria parasites ( $\mathrm{Ng}$ et al., 2017), provided the community with invaluable new tools for the investigation of Plasmodium liver infection and the assessment of anti-plasmodial compounds.

\section{IMMUNE RESPONSES TO PLASMODIUM LIVER INFECTION}

The asymptomatic nature of the liver stage of Plasmodium infection contributed to the long-held assumption that this phase of the parasite's life cycle was also immunologically silent. Maria's work effectively challenged this view and showed that, quite the contrary, this a phase when a rich array of immune responses take place, with a clear impact on infection and pathology. Her early work on HO-1 had already shown that liver infection elicits a potent inflammatory response in the host (Epiphanio et al., 2008). A few years later, work from Maria's lab showed that Plasmodium liver stages induce a potent type I interferon (IFN) response that prompts host cell sensors to activate an immune cell-mediated response (Liehl et al., 2014), the magnitude of which effectively inhibit re-infection in an IFN$\gamma$-dependent way (Liehl et al., 2015). On the other hand, the lab also showed that IFN- $\gamma$ produced by $\gamma \delta$-T cells upon liver-stage infection can have a deleterious effect on the host and promote experimental cerebral malaria (ECM) pathogenesis (Ribot et al., 2019). The enormous potential of the liver stage of infection for immunization against malaria is now firmly established, and Maria has made important contributions to the wholesporozoite-based vaccination approaches. In 2007, her team showed that P36p-deficient $P$. berghei sporozoites can induce protection against a subsequent challenge with fully infectious parasites (Douradinha et al., 2007), contributing to the exploitation of genetically-attenuated parasites (GAP) as vaccination agents against malaria. More than 10 years later, she was involved in a pioneering study by MP that established the proof-of-concept of employing genetically modified rodent malaria parasites, expressing antigens of their human-infective counterparts, as a platform for vaccination against human malaria (Mendes et al., 2018). Collectively, these achievements helped redefine the liver stage of Plasmodium infection as an immunologically rich phase of the parasite's life cycle, once again challenging the prevailing dogma of its immune passiveness.

\section{CROSS-TALK BETWEEN MAMMALIAN INFECTION STAGES}

One of Maria's characteristics is her view of Plasmodium as a complex organism, whose different life cycle stages in the mammalian host should not be viewed independently of each other, as a bidirectional cross-talk exists, in which one stage of mammalian infection may impact the establishment and progression of the other. The identification of HO-1 as a host factor that operates both during the liver (Epiphanio et al., 2008) and the blood (Pamplona et al., 2007) stages of infection by Maria's team nicely illustrates her holistic view of mammalian infection by Plasmodium. This is perhaps even better exemplified by Maria's investigation of the direct impact of blood stage Plasmodium on a subsequent hepatic infection by the same parasite. This work, carried out during SP's PhD, revealed for the first time that an ongoing Plasmodium blood stage infection potently inhibits a subsequent infection by Plasmodium sporozoites. An in depth look at the mechanisms behind this inhibition showed that this process depends at least partly on the iron regulatory hormone hepcidin. This finding unveiled a hostmediated quorum-sensing-like mechanism that regulates superinfection by malaria parasites in regions of high disease endemicity (Portugal et al., 2011).

\section{EXPLOITATION OF HOST RESOURCES BY PLASMODIUM AND HOST RESPONSES TO INFECTION}

Among the most pervasive questions throughout Maria M. Mota's scientific career are "how does the parasite exploit the host for its own benefit?" and "how does the host respond to the invading parasite?" Maria's curiosity about the role of host cell factors and host-mediated processes during liver infection by Plasmodium prompted an array of major achievements that significantly furthered our understanding of the biology of the malaria parasite's sporozoite and liver stages. Looking closely into the infected liver cell, Maria's lab described for the first time a highly dynamic set of hepatocyte actin reorganization events that occur around developing Plasmodium parasites inside hepatic cells, which may contribute to their elimination during development 
in the liver (Gomes-Santos et al., 2012). Soon afterwards, the lab demonstrated that hepatic Plasmodium parasites take up phosphatidylcholine from the host to support their replication (Itoe et al., 2014), and that Plasmodium's vacuolar irontransporter (VIT) homologue plays an important role in iron detoxification, contributing to the parasite's normal development in the liver (Slavic et al., 2016). Maria's team further showed that liver infection by malaria parasites is facilitated by the host's hepatic endoplasmic reticulum (ER)-resident unfolded protein response (UPR) (Inacio et al., 2015), whereas signaling by the host's AMPactivated protein kinase (AMPK) exerts a suppressive effect on hepatic infection (Ruivo et al., 2016). Having contributed to the demonstration that the host's autophagy machinery contributes to the Plasmodium's hepatic development (Thieleke-Matos et al., 2016), Maria's lab later showed that Plasmodium relies on its own upregulated in sporozoites 3 (UIS3) protein to outcompete the autophagy marker microtubule-associated protein 1 light chain 3 (LC3), decreasing its binding to the parasitophorous vacuole membrane (PVM), and thereby avoiding elimination (Real et al., 2018). Maria and her team then showed that this interaction between the parasite's UIS3 and the host's LC3 molecules can be chemically disrupted, inhibiting the parasite's ability to evade the host autophagy response and leading to its elimination (Setua et al., 2020). This array of discoveries has brought us closer to understanding why Plasmodium sporozoites "choose" the hepatocyte as their initial site of replication in the mammalian host, a key question in this field of research.

\section{HOST-MEDIATED MODULATION OF INFECTION}

Maria's conviction that Plasmodium infection can be modulated by the host prompted her and her team to investigate whether the host's nutritional status influences the course of infection and pathology. This study unveiled a novel mechanism whereby the Plasmodium kinase KIN acts as a sensor that enables the parasite to modulate its replication rate in accordance with the host's nutritional status (Mancio-Silva et al., 2017). This discovery was reported close to another one, addressing the modulation of Plasmodium liver infection by the host's dietary intake. This study showed that the oxidative stress induced by a high-fat diet causes the death of intra-hepatic parasites, leading to a major decrease in the overall Plasmodium liver load, and significantly decreasing the severity of the ensuing disease (Zuzarte-Luis et al., 2017). These discoveries have contributed decisively to enhancing the notion that the mammalian host plays a critical role in the development of malaria disease, and that the latter can be influenced through the modulation of the parasite's environment inside the former.

\section{FINAL REMARKS}

Maria's achievements as a malaria researcher have earned her worldwide recognition in the community. Her appointments as a Howard Hughes Medical Institute (HHMI) International Research Scholar from 2005 to 2010, and as a European Molecular Biology
Organization (EMBO) Member in 2016 constitute significant recognitions of both her accomplishments and her potential. Besides her scientific excellence, Maria has a captivating personality and is an engaging communicator, who has brought malaria research to the spotlight in Portugal and beyond, through her multiple public appearances in the media and her ability to entice her audiences. A staunch advocate for women's rights and equal education opportunities, she commonly features in the list of the most influential women in Portugal and has earned numerous national and international awards that further enhanced her standing in the malaria research community. She has helped foster iMM's reputation and recognition at both the national and international levels, and her actions have had an enormous impact on science policies in Portugal as a whole. She has inspired and guided more than one generation of scientists, many of whom have grown to lead their independent research labs.

Maria M. Mota's scientific career is an inspiring example of commitment to science, enthusiasm and excellence. She was able to carve a research niche that earned her international reputation and contributed greatly to Portugal's prominence in malaria research over the last couple of decades (Prudencio, 2021). Naturally, her achievements owe immensely to the efforts and dedication of her research team. Over the years, her laboratory has hosted numerous postdoctoral researchers, $\mathrm{PhD}$ and Master's students, laboratory technicians and managers, and visiting scientists, all of whom have been inspired by Maria, and all of whom have contributed enormously to the success of her research. Equally relevant, the respect earned by Maria in the scientific community has enabled her to establish an extended network of outstanding collaborators, to whom she also owes much of her success. As Maria likes to say, ideas appear when people come together and talk to each other about their science. Maria's ability to foster discussion, both within and beyond her own lab, has always been one of the distinctive features of her scientific drive. As Executive Director of iMM, Maria created the institute's motto "chasing questions", because she deeply believes that the formulation of the most creative questions is the key to all major scientific advances.

Maria's brain is constantly teeming with new interrogations that drive her creativity and fuel her passion for science. While it may not be easy to predict exactly what scientific achievements Maria's future will bring, it is certainly not hard to forecast that she will continue challenging the borders of our knowledge of the liver stage of Plasmodium infection. As such, we can be pretty confident that many fascinating discoveries still lie ahead in her path through science. Stay tuned!

\section{AUTHOR CONTRIBUTIONS}

All authors contributed to the article and approved the submitted version.

\section{ACKNOWLEDGMENTS}

Inês Domingues and Joana Costa are gratefully acknowledged for various discussions and for their critical review of the manuscript. 


\section{REFERENCES}

Albuquerque, S. S., Carret, C., Grosso, A. R., Tarun, A. S., Peng, X., Kappe, S. H., et al. (2009). Host Cell Transcriptional Profiling During Malaria Liver Stage Infection Reveals a Coordinated and Sequential Set of Biological Events. BMC Genomics 10, 270. doi: 10.1186/1471-2164-10-270

Carrolo, M., Giordano, S., Cabrita-Santos, L., Corso, S., Vigario, A. M., Silva, S., et al. (2003). Hepatocyte Growth Factor and Its Receptor Are Required for Malaria Infection. Nat. Med. 9, 1363-1369. doi: 10.1038/nm947

Cunha-Rodrigues, M., Portugal, S., Prudencio, M., Goncalves, L. A., Casalou, C., Buger, D., et al. (2008). Genistein-Supplemented Diet Decreases Malaria Liver Infection in Mice and Constitutes a Potential Prophylactic Strategy. PloS One 3, e2732. doi: 10.1371/journal.pone.0002732

da Cruz, F. P., Martin, C., Buchholz, K., Lafuente-Monasterio, M. J., Rodrigues, T., Sonnichsen, B., et al. (2012). Drug Screen Targeted at Plasmodium Liver Stages Identifies a Potent Multistage Antimalarial Drug. J. Infect. Dis. 205, 1278-1286. doi: 10.1093/infdis/jis184

Derbyshire, E. R., Prudencio, M., Mota, M. M., and Clardy, J. (2012). Liver-Stage Malaria Parasites Vulnerable to Diverse Chemical Scaffolds. Proc. Natl. Acad. Sci. U. S. A. 109, 8511-8516. doi: 10.1073/pnas.1118370109

Douradinha, B., van Dijk, M. R., Ataide, R., van Gemert, G. J., Thompson, J., Franetich, J. F., et al. (2007). Genetically Attenuated P36p-Deficient Plasmodium Berghei Sporozoites Confer Long-Lasting and Partial Cross-Species Protection. Int. J. Parasitol. 37, 1511-1519. doi: 10.1016/j.ijpara.2007.05.005

Epiphanio, S., Campos, M. G., Pamplona, A., Carapau, D., Pena, A. C., Ataide, R., et al. (2010). VEGF Promotes Malaria-Associated Acute Lung Injury in Mice. PloS Pathog. 6, e1000916. doi: 10.1371/journal.ppat.1000916

Epiphanio, S., Mikolajczak, S. A., Goncalves, L. A., Pamplona, A., Portugal, S., Albuquerque, S., et al. (2008). Heme Oxygenase-1 Is an Anti-Inflammatory Host Factor That Promotes Murine Plasmodium Liver Infection. Cell Host Microbe 3, 331-338. doi: 10.1016/j.chom.2008.04.003

Gomes-Santos, C. S., Braks, J., Prudencio, M., Carret, C., Gomes, A. R., Pain, A., et al. (2011). Transition of Plasmodium Sporozoites Into Liver Stage-Like Forms Is Regulated by the RNA Binding Protein Pumilio. PloS Pathog. 7, e1002046. doi: 10.1371/journal.ppat.1002046

Gomes-Santos, C. S., Itoe, M. A., Afonso, C., Henriques, R., Gardner, R., Sepulveda, N., et al. (2012). Highly Dynamic Host Actin Reorganization Around Developing Plasmodium Inside Hepatocytes. PloS One 7, e29408. doi: 10.1371/journal.pone.0029408

Hanson, K. K., Ressurreicao, A. S., Buchholz, K., Prudencio, M., Herman-Ornelas, J. D., Rebelo, M., et al. (2013). Torins Are Potent Antimalarials That Block Replenishment of Plasmodium Liver Stage Parasitophorous Vacuole Membrane Proteins. Proc. Natl. Acad. Sci. U. S. A. 110, E2838-E2847. doi: 10.1073/pnas.1306097110

Inacio, P., Zuzarte-Luis, V., Ruivo, M. T., Falkard, B., Nagaraj, N., Rooijers, K., et al. (2015). Parasite-Induced ER Stress Response in Hepatocytes Facilitates Plasmodium Liver Stage Infection. EMBO Rep. 16, 955-964. doi: 10.15252/ embr.201439979

Itoe, M. A., Sampaio, J. L., Cabal, G. G., Real, E., Zuzarte-Luis, V., March, S., et al. (2014). Host Cell Phosphatidylcholine Is a Key Mediator of Malaria Parasite Survival During Liver Stage Infection. Cell Host Microbe 16, 778-786. doi: 10.1016/j.chom.2014.11.006

Langhorne, J., Buffet, P., Galinski, M., Good, M., Harty, J., Leroy, D., et al. (2011). The Relevance of Non-Human Primate and Rodent Malaria Models for Humans. Malar. J. 10, 23. doi: 10.1186/1475-2875-10-23

Leiriao, P., Albuquerque, S. S., Corso, S., van Gemert, G. J., Sauerwein, R. W., Rodriguez, A., et al. (2005). HGF/MET Signalling Protects PlasmodiumInfected Host Cells From Apoptosis. Cell Microbiol. 7, 603-609. doi: 10.1111/j.1462-5822.2004.00490.x

Liehl, P., Franca, A. R., Prudencio, M., Latz, E., Zaidman-Remy, A., and Mota, M. M. (2010). Phosphothioate Oligodeoxynucleotides Inhibit Plasmodium Sporozoite Gliding Motility. Cell Microbiol. 12, 506-515. doi: 10.1111/j.14625822.2009.01411.x

Liehl, P., Meireles, P., Albuquerque, I. S., Pinkevych, M., Baptista, F., Mota, M. M., et al. (2015). Innate Immunity Induced by Plasmodium Liver Infection Inhibits Malaria Reinfections. Infect. Immun. 83, 1172-1180. doi: 10.1128/ IAI.02796-14
Liehl, P., Zuzarte-Luis, V., Chan, J., Zillinger, T., Baptista, F., Carapau, D., et al. (2014). Host-Cell Sensors for Plasmodium Activate Innate Immunity Against Liver-Stage Infection. Nat. Med. 20, 47-53. doi: 10.1038/nm.3424

Mancio-Silva, L., Slavic, K., Grilo Ruivo, M. T., Grosso, A. R., Modrzynska, K. K., Vera, I. M., et al. (2017). Nutrient Sensing Modulates Malaria Parasite Virulence. Nature 547, 213-216. doi: 10.1038/nature23009

March, S., Ng, S., Velmurugan, S., Galstian, A., Shan, J., Logan, D. J., et al. (2013). A Microscale Human Liver Platform That Supports the Hepatic Stages of Plasmodium Falciparum and Vivax. Cell Host Microbe 14, 104-115. doi: 10.1016/j.chom.2013.06.005

Mello-Vieira, J., Enguita, F. J., de Koning-Ward, T. F., Zuzarte-Luis, V., and Mota, M. M. (2020). Plasmodium Translocon Component EXP2 Facilitates Hepatocyte Invasion. Nat. Commun. 11, 5654. doi: 10.1038/s41467-02019492-4

Mendes, A. M., Machado, M., Goncalves-Rosa, N., Reuling, I. J., Foquet, L., Marques, C., et al. (2018). A Plasmodium Berghei Sporozoite-Based Vaccination Platform Against Human Malaria. NPJ Vaccines 3, 33. doi: 10.1038/s41541-018-0068-2

Mota, M. M., Hafalla, J. C., and Rodriguez, A. (2002). Migration Through Host Cells Activates Plasmodium Sporozoites for Infection. Nat. Med. 8, 1318-1322. doi: $10.1038 / \mathrm{nm} 785$

Mota, M. M., Pradel, G., Vanderberg, J. P., Hafalla, J. C., Frevert, U., Nussenzweig, R. S., et al. (2001). Migration of Plasmodium Sporozoites Through Cells Before Infection. Science 291, 141-144. doi: 10.1126/science.291.5501.141

Ng, S., March, S., Galstian, A., Gural, N., Stevens, K. R., Mota, M. M., et al. (2017). Towards a Humanized Mouse Model of Liver Stage Malaria Using Ectopic Artificial Livers. Sci. Rep. 7, 45424. doi: 10.1038/srep45424

Ng, S., Schwartz, R. E., March, S., Galstian, A., Gural, N., Shan, J., et al. (2015). Human iPSC-Derived Hepatocyte-Like Cells Support Plasmodium Liver-Stage Infection In Vitro. Stem Cell Rep. 4, 348-359. doi: 10.1016/j.stemcr.2015.01.002

Pamplona, A., Ferreira, A., Balla, J., Jeney, V., Balla, G., Epiphanio, S., et al. (2007). Heme Oxygenase-1 and Carbon Monoxide Suppress the Pathogenesis of Experimental Cerebral Malaria. Nat. Med. 13, 703-710. doi: 10.1038/nm1586

Parvanova, I., Epiphanio, S., Fauq, A., Golde, T. E., Prudencio, M., and Mota, M. M. (2009). A Small Molecule Inhibitor of Signal Peptide Peptidase Inhibits Plasmodium Development in the Liver and Decreases Malaria Severity. PloS One 4, e5078. doi: 10.1371/journal.pone.0005078

Ploemen, I. H., Prudencio, M., Douradinha, B. G., Ramesar, J., Fonager, J., van Gemert, G. J., et al. (2009). Visualisation and Quantitative Analysis of the Rodent Malaria Liver Stage by Real Time Imaging. PloS One 4, e7881. doi: 10.1371/journal.pone.0007881

Portugal, S., Carret, C., Recker, M., Armitage, A. E., Goncalves, L. A., Epiphanio, S., et al. (2011). Host-Mediated Regulation of Superinfection in Malaria. Nat. Med. 17, 732-737. doi: 10.1038/nm.2368

Prudencio, M. (2021). Portugal's Prominence in Malaria Research: How a Small Country Became a Key Player in European Research on One of the World's Deadliest Diseases. EMBO Rep. 22, e51692. doi: 10.15252/embr.202051692

Prudencio, M., Mota, M. M., and Mendes, A. M. (2011). A Toolbox to Study Liver Stage Malaria. Trends Parasitol. 27, 565-574. doi: 10.1016/j.pt.2011.09.004

Prudencio, M., Rodrigues, C. D., Ataide, R., and Mota, M. M. (2008). Dissecting In Vitro Host Cell Infection by Plasmodium Sporozoites Using Flow Cytometry. Cell Microbiol. 10, 218-224. doi: 10.1111/j.1462-5822.2007.01032.x

Prudencio, M., Rodrigues, C. D., Hannus, M., Martin, C., Real, E., Goncalves, L. A., et al. (2008). Kinome-Wide RNAi Screen Implicates at Least 5 Host Hepatocyte Kinases in Plasmodium Sporozoite Infection. PloS Pathog. 4, e1000201. doi: 10.1371/journal.ppat.1000201

Prudencio, M., Rodriguez, A., and Mota, M. M. (2006). The Silent Path to Thousands of Merozoites: The Plasmodium Liver Stage. Nat. Rev. Microbiol. 4, 849-856. doi: 10.1038/nrmicro1529

Real, E., Rodrigues, L., Cabal, G. G., Enguita, F. J., Mancio-Silva, L., Mello-Vieira, J., et al. (2018). Plasmodium UIS3 Sequesters Host LC3 to Avoid Elimination by Autophagy in Hepatocytes. Nat. Microbiol. 3, 17-25. doi: 10.1038/s41564017-0054-x

Ribot, J. C., Neres, R., Zuzarte-Luis, V., Gomes, A. Q., Mancio-Silva, L., Mensurado, S., et al. (2019). Gammadelta-T Cells Promote IFN-GammaDependent Plasmodium Pathogenesis Upon Liver-Stage Infection. Proc. Natl. Acad. Sci. U. S. A. 116, 9979-9988. doi: 10.1073/pnas.1814440116 
Rodrigues, C. D., Hannus, M., Prudencio, M., Martin, C., Goncalves, L. A., Portugal, S., et al. (2008). Host Scavenger Receptor SR-BI Plays a Dual Role in the Establishment of Malaria Parasite Liver Infection. Cell Host Microbe 4, 271-282. doi: 10.1016/j.chom.2008.07.012

Ruivo, M. T. G., Vera, I. M., Sales-Dias, J., Meireles, P., Gural, N., Bhatia, S. N., et al. (2016). Host AMPK Is a Modulator of Plasmodium Liver Infection. Cell Rep. 16, 2539-2545. doi: 10.1016/j.celrep.2016.08.001

Setua, S., Enguita, F. J., Chora, A. F., Ranga-Prasad, H., Lahree, A., Marques, S., et al. (2020). Disrupting Plasmodium UIS3-Host LC3 Interaction With a Small Molecule Causes Parasite Elimination From Host Cells. Commun. Biol. 3, 688. doi: 10.1038/s42003-020-01422-1

Shortt, H. E., Garnham, P. C., and Malamos, B. (1948). The Pre-Erythrocytic Stage of Mammalian Malaria. Br. Med. J. 1, 192-194. doi: 10.1136/bmj.1.4543.192

Slavic, K., Krishna, S., Lahree, A., Bouyer, G., Hanson, K. K., Vera, I., et al. (2016). A Vacuolar Iron-Transporter Homologue Acts as a Detoxifier in Plasmodium. Nat. Commun. 7, 10403. doi: 10.1038/ncomms10403

Thieleke-Matos, C., Lopes da Silva, M., Cabrita-Santos, L., Portal, M. D., Rodrigues, I. P., Zuzarte-Luis, V., et al. (2016). Host Cell Autophagy Contributes to Plasmodium Liver Development. Cell Microbiol. 18, 437-450. doi: $10.1111 / \mathrm{cmi} .12524$

Zuzarte-Luis, V., Mello-Vieira, J., Marreiros, I. M., Liehl, P., Chora, A. F., Carret, C. K., et al. (2017). Dietary Alterations Modulate Susceptibility to Plasmodium Infection. Nat. Microbiol. 2, 1600-1607. doi: 10.1038/s41564-017-0025-2
Zuzarte-Luis, V., Mota, M. M., and Vigario, A. M. (2014). Malaria Infections: What and How can Mice Teach Us. J. Immunol. Methods 410, 113-122. doi: 10.1016/j.jim.2014.05.001

Zuzarte-Luis, V., Sales-Dias, J., and Mota, M. M. (2014). Simple, Sensitive and Quantitative Bioluminescence Assay for Determination of Malaria Pre-Patent Period. Malar. J. 13, 15. doi: 10.1186/1475-2875-13-15

Conflict of Interest: The authors declare that the research was conducted in the absence of any commercial or financial relationships that could be construed as a potential conflict of interest.

Publisher's Note: All claims expressed in this article are solely those of the authors and do not necessarily represent those of their affiliated organizations, or those of the publisher, the editors and the reviewers. Any product that may be evaluated in this article, or claim that may be made by its manufacturer, is not guaranteed or endorsed by the publisher.

Copyright (c) 2022 Portugal, Rodriguez and Prudêncio. This is an open-access article distributed under the terms of the Creative Commons Attribution License (CC BY). The use, distribution or reproduction in other forums is permitted, provided the original author(s) and the copyright owner(s) are credited and that the original publication in this journal is cited, in accordance with accepted academic practice. No use, distribution or reproduction is permitted which does not comply with these terms. 